Brain, Behavior and Evolution
Brain Behav Evol 2010;75:262-270

DOI: $10.1159 / 000314901$
Received: December 4, 2009

Returned for revision: December 30, 2009

Accepted after revision: May 4, 2010

Published online: June 28, 2010

\title{
Effects of Amphetamine on Conditioned Place Preference and Locomotion in the Male Green Tree Frog, Hyla cinerea
}

\author{
Gina M. Presley ${ }^{\mathrm{a}}$ William Lonergan $^{\mathrm{b}}$ Joanne $\mathrm{Chu} \mathrm{c}^{\mathrm{c}}$ \\ ${ }^{a}$ Department of Justice Science, University of Alabama at Birmingham, Birmingham, Ala., ${ }^{\mathrm{b} C h r o n i c ~ V i r a l ~ D i s e a s e s ~}$ \\ Branch, Division of Viral and Rickettsial Diseases, Centers for Disease Control and Prevention, Atlanta, Ga., and \\ 'Department of Biology, Agnes Scott College, Decatur, Ga., USA
}

\section{Key Words}

Amphetamine $\cdot$ Amphibian $\cdot$ Catecholamine $\cdot$ Conditioned place preference $\cdot$ Dopamine $\cdot$ Frog $\cdot$ Hyla cinerea $\cdot$

Locomotor activity $\cdot$ Motivation $\cdot$ Motor $\cdot$ Non-mammal . Reward

\begin{abstract}
Neural systems mediating motivation and reward have been well described in mammalian model systems, especially with reference to reward properties of drugs of abuse. Far less is known of the neural mechanisms underlying motivation and reward in non-mammals. The behavioral procedure conditioned place preference (CPP) is often used to quantify reward properties of psychoactive drugs. The indirect dopamine agonist $d$-amphetamine (AMPH) is known for its properties for inducing CPP in mammals and for inducing dose-related stereotypic movements. We used the green tree frog, Hyla cinerea, to examine whether AMPH could induce both CPP and a dose response change in motor behaviors. We demonstrated that $H$. cinerea can show place conditioning to AMPH following 14 days of training and that $\mathrm{AMPH}$ can cause reversal of a strong baseline place preference. Amphetamine-treated animals ( $20 \mathrm{mg} / \mathrm{kg}$ b.w.) received the drug paired with the previously non-preferred context, and vehicle paired with the preferred context. Control animals received vehicle in both preferred and non-preferred contexts. Amphetamine-treated animals switched context pref-
\end{abstract}

erence following conditioning, whereas control animals did not. We also demonstrated in an open-field experiment that AMPH did not cause any noticeable changes in motor movement or behaviors across a range of doses $(0,10,20 \mathrm{mg} / \mathrm{kg}$ b.w.). This study represents the first examination of the behavioral effects of AMPH in amphibians. These results may contribute to a better understanding of the function and pharmacology of a reward system that may mediate natural behaviors in frogs and other vertebrates.

Copyright $\odot 2010$ S. Karger AG, Basel

\section{Introduction}

Many animals can learn to associate environmental cues with the presence of natural rewards. Such animals will seek out or approach stimuli that contain or are associated with positive benefits (e.g. food, water, safety or sexual opportunities) [Tzschentke, 2007]. In vertebrates, the ability to associate environments or conditions with positive stimuli is in part due to the evolution of a central reward system [Cohen and Blum, 2002; Watson and Platt, 2008]. One critical function of a reward system is to enhance occurrence of behaviors that enhance survival and reproductive fitness and diminish those that may contain a biological cost [Hinde, 1982; Watson and Platt, 2008].

The neural circuitry underlying reward processing in vertebrates has been thoroughly examined in rodent

\section{KARGER}

두 2010 S. Karger AG, Basel

Fax +41613061234 E-Mail karger@karger.ch www.karger.com www.karger.com/bbe
Joanne Chu

Department of Biology, Agnes Scott College

141 E. College Ave

Decatur, GA 30030 (USA)

Tel. +1 404471 5270, Fax +1 404471 5368, E-Mail jchu@agnesscott.edu 
models [Berridge and Robinson, 1998; Berridge, 2007]. Multiple behavioral and anatomical studies have shown that a critical component of the mammalian reward system consists of dopaminergic neurons. These dopamine (DA) pathways originate in the ventral tegmental area and substantial nigra and send projections to limbic regions such as the nucleus accumbens and striatum [Berridge and Robinson, 1998]. In contrast to the work on rodents, there has been no systematic investigation of reward systems across other vertebrate taxa, although there is now strong behavioral evidence for dopamine-based reward systems in birds [Akins et al., 2004; Levens and Akins, 2004; Akins and Geary, 2008; He et al., 2009] and to a much lesser extent fish [Darland and Dowling, 2001] and reptiles [Lanuza et al., 2008]. Whether an analogous reward system exists in amphibians has not yet been investigated. Overall there is also little understanding of how such reward systems mediate natural behaviors in most animals or how such systems evolved.

One experimental method commonly used to assess the strength of a potentially rewarding stimulus is the conditioned place preference (CPP) paradigm. CPP is commonly used to assess the magnitude of reward associated with drugs of abuse [Bardo and Bevins, 2000]. CPP is also used for assessing reward properties of natural stimuli, such as food [Jarosz et al., 2007], water [Agmo et al., 1993], social interactions [Calcagnetti and Schechter, 1992; Douglas et al., 2004; Panksepp and Lahvis, 2006], or sexual opportunities [Martinez and Paredes, 2001; Douglas et al., 2004; Meerts and Clark, 2007]. Typically, a CPP procedure consists of a simple experimental chamber that has been spatially divided into two contrasting environments. Animals receive alternating exposures to each environmental context, one is paired with a reward stimulus, the other is paired with a neutral stimulus. Following repeated exposures, animals are given a final preference trial in which they are allowed to freely choose between environments, absent the conditioning stimuli. Increased time spent in the environment previously paired with the reward is interpreted as evidence that the animal has been conditioned to connect a specific location with reward. This interpretation is especially strong when the stimulus-context pair is determined by pairing the reward stimulus with the subject's initial 'non-preferred' context. The simplicity of this behavioral manipulation has readily allowed this paradigm to be used to assess reward properties of many drugs and other stimuli in both non-mammals and mammals. CPP studies have been used to examine drug reward properties of the psychostimulants amphetamine or cocaine in a variety of taxa including mammals [Sherman et al., 1980; Bardo and Bevins, 2000], teleosts [Darland and Dowling, 2001; Ninkovic and BallyCuif, 2006], crustaceans [Panksepp and Huber, 2004] and birds [Levens and Akins, 2001; Akins et al., 2004]. The known pharmacology of these drugs strongly suggests that these conditioned behaviors are mediated largely through DA-based mechanisms and that reward properties of these drugs are evolutionarily conserved.

Anurans (frogs and toads) are an excellent model for studies to further our understanding of the evolution of reward systems. Although few studies have directly examined reward-related behaviors in amphibians, anurans can be successfully trained in associative learning tasks, such as active avoidance [Martof, 1962] and various maze paradigms [Martof, 1962; Grubb, 1976; Brattstrom, 1990; Bilbo et al., 2000; Chu and Wilczynski, 2007], all of which are driven by learned associations with a reward stimulus (or avoidance of punishment).

In contrast to limited behavioral investigations of a putative reward system, there have been multiple studies in anurans of the anatomical substrates of a reward system. In mammals, the monoaminergic systems, especially dopamine and other catecholamines, play important roles in mediating reward. Dopaminergic populations and pathways have been well described in several frog species and a mesolimbic dopamine pathway has been identified [Marin et al., 1995, 1997]. Anatomical studies of basal forebrain dopamine pathways in frogs have indicated a strong homology with mammalian dopamine circuits [Gonzalez et al., 1993; Marin et al., 1995, 1997]. Other studies have shown that other catecholamine and serotonin systems also are highly anatomically conserved between anurans and mammals [Smeets, 1994; Smeets and Gonzalez, 2000; Zhao and Debski, 2005; SanchezCamacho et al., 2006]. It is unknown which neurotransmitter systems mediate reward behaviors in frogs.

We investigated whether Hyla cinerea, the green tree frog, possesses a reward system pharmacologically homologous to mammals using the psychostimulant amphetamine and CPP. In mammals, the psychoactive drug d-amphetamine (AMPH) is well known for its classic effects to induce conditioned place preference in mammals [Bardo and Bevins, 2000]. The effects of systemic AMPH administration are complex and known to influence multiple neurotransmitter systems, especially dopamine, norepinephrine and serotonin [Seiden et al., 1993]. There are also multiple mechanisms by which AMPH exerts its action. AMPH inhibits monoamine oxidase activity, induces pre-synaptic release and blocks reuptake [Segal and Kuczenski, 1994]. We chose to use AMPH, a drug well 
described for these complex pharmacological effects, to examine reward conditioning, as so little is currently known about the function or pharmacology of the monoaminergic systems in frogs. Anatomical studies have documented and described evolutionarily conserved monoaminergic systems in frogs [Smeets, 1994; Smeets and Gonzalez, 2000; Zhao and Debski, 2005; Sanchez-Camacho et al., 2006], in particular the mesolimbic dopamine system [Marin et al., 1995, 1997]. Due to the anatomical evidence of supporting monoaminergic systems, we hypothesized that $H$. cinerea would show CPP to AMPH. If $\mathrm{AMPH}$ induces place preference in frogs, these findings would support the hypothesis that frogs possess neurocircuitry for drug reward similar to that of mammals. These findings would indirectly suggest that the mesolimbic dopamine system and other monoaminergic systems in amphibians could regulate other reward-mediated behaviors critical for survival.

Anurans engage in a variety of socially mediated motivated behaviors such as courtship (advertisement) and territorial calling behavior, amplectic clasping (the amphibian mating posture) and parental behavior [Heatwole and Sullivan, 1995]. Many socially mediated behaviors have been shown to involve mesolimbic dopamine in mammals, but we have little understanding of the neurochemical mechanisms that mediate such behaviors in frogs and other amphibians.

In addition to its reward properties, $\mathrm{AMPH}$ is also classically known to increase spontaneous locomotor behaviors in mammals in a dose-dependent manner [Cole, 1967]. The effects of acute treatment of AMPH on motor behaviors has been examined in birds [Cheng et al., 1975; Goodman, 1981; Idemudia and McMillan, 1984] and fish [Munro, 1986; Lett and Grant, 1989]. However, AMPH effects on locomotion are unknown for amphibians or reptiles. In a separate set of experiments, we examined the dose-response effects of AMPH on spontaneous open field behaviors using the conditioning chamber to examine motor response. We hypothesized that AMPH would increase spontaneous locomotor behaviors in frogs. Furthermore, we hypothesized that increased movement would be positively correlated with increased $\mathrm{AMPH}$ dose.

\section{Materials and Methods}

\section{Subjects}

Wild-caught breeding-condition adult male Hyla cinerea (Pine Mountain, Ga., USA) were used in these studies. Animals were group housed in a semi-aquatic habitat in 40-liter aquaria.
Average weight per animal was $8 \mathrm{~g}$. Animals were kept on a reversed $12 \mathrm{~L}: 12 \mathrm{D}$ light cycle (lights off at 9 a.m.). To simulate natural conditions, the room was maintained at $28^{\circ} \mathrm{C}$ and animals were misted daily to maintain higher than ambient humidity. Animals were fed live crickets twice per week. As frogs are nocturnal, all experiments were conducted during the dark phase of the light cycle. All procedures were carried out in accordance with protocols approved by the Morehouse School of Medicine institutional animal care and use committee.

\section{Drugs}

AMPH (National Institutes on Drug Abuse, Bethesda, Md., USA) was dissolved in amphibian Ringer's solution just prior to the start of each experiment $(1 \mathrm{mg} / \mathrm{ml})$. Animals were injected interperitoneally. Amphibian Ringer's solution was used as a vehicle control.

\section{Behavioral Apparatus}

Using an aquarium of 10 gallons (approx. 38 liters) for the basic structure, four identical place preference chambers were designed and built to examine CPP in tree frogs. This particular species possesses a strong aversion to resting on horizontal surfaces. In order to minimize aversion to the chamber, the inside of each chamber contained angled floors made from 3-mm-thick Plexiglas that sloped upward from the middle of the chamber at $45^{\circ}$. Each angled floor began $1.5 \mathrm{~cm}$ from the midline of the chamber. This space allowed the animal to be placed in a neutral space when placed in the undivided chamber. Each chamber consisted of two halves of a contrasting color and texture. The black half consisted of black embroidery board placed on the floor and walls of the chamber; the white half consisted of smooth white opaque contact paper lining the floor and walls. The black and white contexts were separated with a Plexiglas dividing partition that was also lined with the appropriate contrasting material (fig. 1). A clear Plexiglas covering was used over each chamber to allow unobstructed monitoring of the subject's behavior from above. Subjects were videotaped on the conditioning test day and for all locomotor trials for later analysis. All behavior was scored blind to drug condition.

\section{Conditioned Place Preference to AMPH}

Context Preference Procedure

An initial context preference was assessed for each animal prior to drug conditioning. Each animal was exposed to one chamber side of a divided chamber for $30 \mathrm{~min}$ per day for 4 days. Chamber side exposure alternated each day so that animals were exposed to a total of two days of black and two of white contexts. On the fifth day, the dividing partition was removed. Context preference was determined by the total amount of time spent in each side of the chamber out of a 30-min trial.

Drug-Conditioning Procedure

During drug-conditioning trials, the dividing partition was placed in the chamber. Each animal received a single daily i.p. injection of $20 \mathrm{mg} / \mathrm{kg}$ b.w. of AMPH or an equivalent volume of vehicle. Following the injection and prior to being placed in the conditioning chamber, each frog was held in a small dark box for $5 \mathrm{~min}$ to recover from handling. Animals were exposed to black or white contexts for $30 \mathrm{~min}$ each day. Contexts were alternated each day. Experimental animals $(n=8)$ received a total of seven 


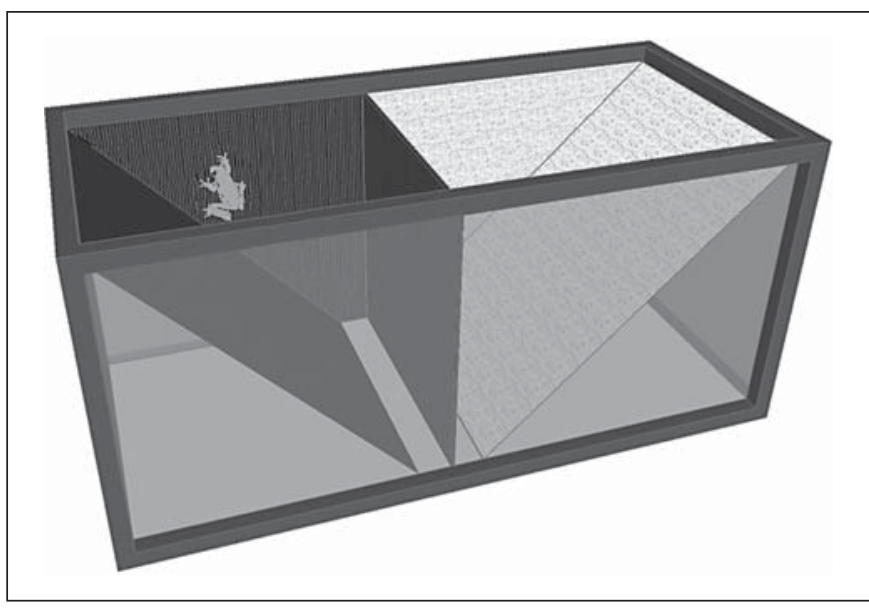

Fig. 1. Schematic of the place-conditioning chamber, designed for tree frogs. Schematic shows the chamber with the dividing partition in place. During the test day of the conditioning experiment and for all locomotor experiments, the partition was removed.

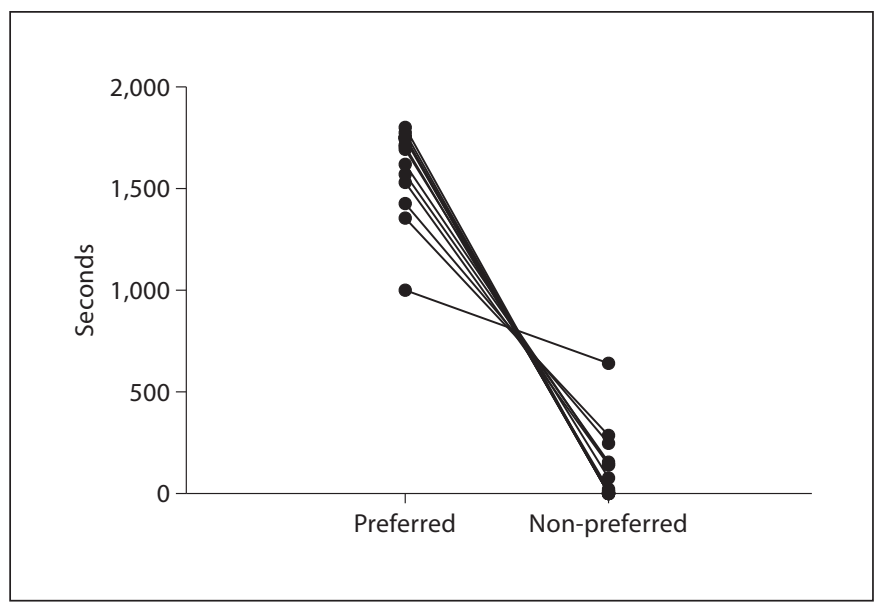

Fig. 2. The amount of time each animal spent in the preferred and non-preferred contexts following 4 days of pre-exposure to the conditioning chamber. Frogs showed a strong baseline preference for one of the contexts $(\mathrm{p}<0.0001)$. days of AMPH paired with the initial non-preferred context and seven days of vehicle paired with the preferred context. Control animals $(n=8)$ received saline paired with both non-preferred and preferred sides. On the fifteenth day the partition was removed so that each animal could freely access the entire chamber for $30 \mathrm{~min}$. Total accumulated time spent on each side of the chamber was quantified from videotape for statistical comparisons.

\section{AMPH Effects on Locomotor Response, a Dose-Response}

Study

Locomotor responses to 0,10 , and $20 \mathrm{mg} / \mathrm{kg} \mathrm{AMPH} \mathrm{(} \mathrm{n}=5$, each group) were examined using the undivided place preference chamber as a behavioral arena. On day 1 , frogs received an injection of vehicle and were placed in a dark box to recover from handling. Five minutes later each frog was allowed access to the entire chamber for $30 \mathrm{~min}$ (baseline). On day 2, each frog was given a single injection of AMPH or vehicle and the procedure was repeated (test). All subjects were videotaped while in the chamber. Tree frogs rarely hop; most forward motion is through intermittent forward crawling or climbing, using all four limbs. The number of times each frog began to move forward (moved all four limbs) was counted for each $30 \mathrm{~min}$ interval (crawls or climbs). Statistical analyses were performed on both relative (the number of moves initiated on day 2 minus moves made on day 1) and absolute (number of moves initiated on day 2 only) moves.

\section{Statistical Analysis}

All experiments were analyzed using parametric statistics. In the CPP experiment, two-tailed, paired t tests were used to determine initial context preference and to compare time spent on the preferred side before and after conditioning for AMPH and vehicle-conditioned groups. To examine relative changes in preference, a one-tailed t test was used to compare AMPH versus vehicle-conditioned animals. To examine locomotor response to
AMPH, a two-way repeated measure ANOVA was performed using drug dose $(0,10,20 \mathrm{mg} / \mathrm{kg}$ b.w.) and time (baseline vs. test) as between group comparisons, followed by Bonferroni post hoc tests. All figures are shown as mean \pm SEM.

\section{Results}

\section{Conditioned Place Preference to AMPH}

We examined AMPH-induced place conditioning following 14 days of training. Each animal's initial preference strength for context was measured following 4 days of pre-exposure to the chamber. A paired t test comparing time spent in 'preferred' versus 'non-preferred' contexts indicated a strong initial preference prior to conditioning $(\mathrm{t}(15)=15.91, \mathrm{p}<0.0001$; fig. 2). Interestingly, specific color preference was evenly divided across experimental treatments (table 1). Following 14 days of conditioning, AMPH-treated animals showed a significant decrease in time spent in the initial 'preferred' context $(t(7)=4.6, p=0.003$; fig. 3a). Control animals showed no significant change in time spent in the initial 'preferred' context. Controls maintained the same context preference $(t(7)=1.86, p=0.10$; fig. 3a). AMPH conditioned animals also showed a significant change in the relative amount of time spent on the non-preferred side before and after conditioning compared to control animals $(t(14)=1.962, p=0.03$; fig. 3b). 


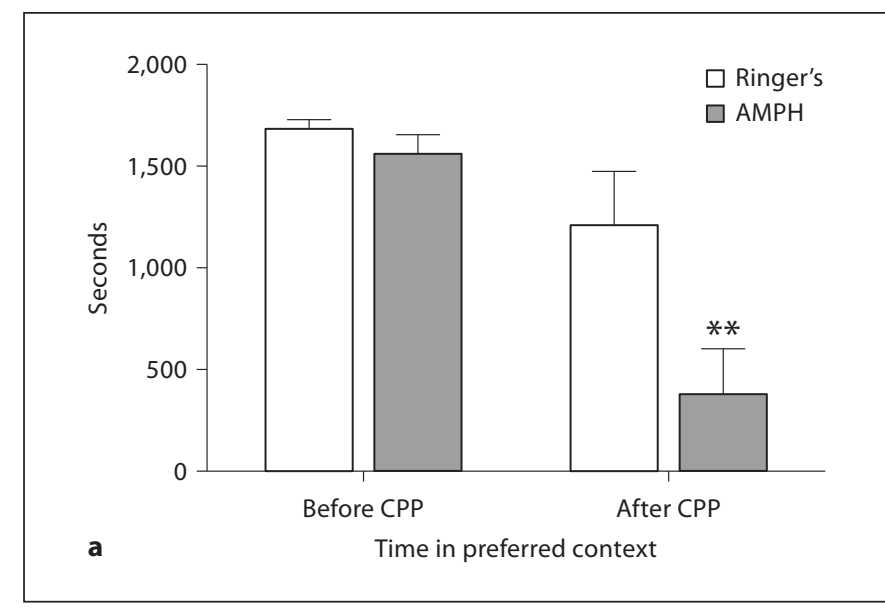

Fig. 3. a The amount of time spent in the initial 'preferred' context before and after 14 days of conditioning. Frogs receiving AMPH paired with the non-preferred context showed decreased time spent in the preferred context following conditioning. Control

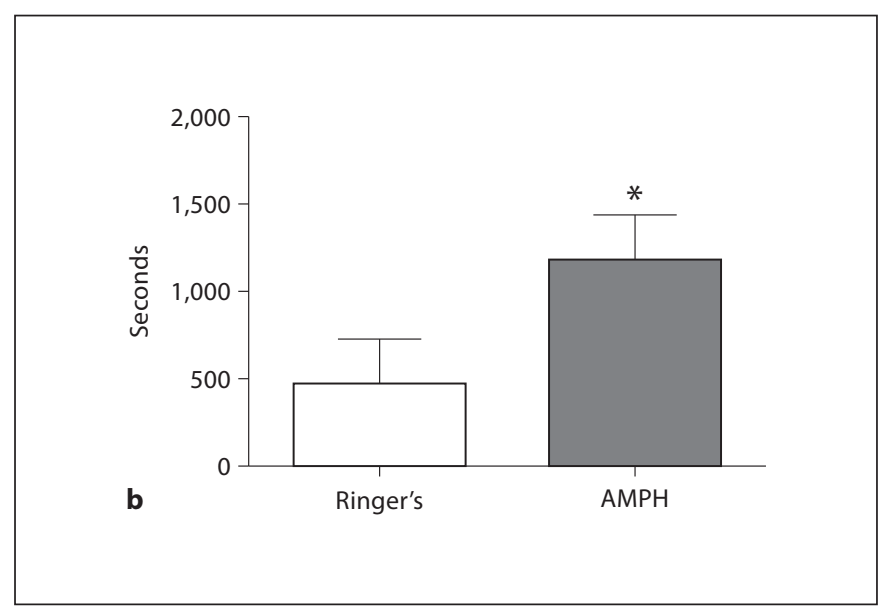

animals did not. $\mathbf{b}$ The strength of conditioned preference. The change in the amount of time spent in the non-preferred side following conditioning, relative to baseline. ${ }^{*} \mathrm{p}<0.05,{ }^{* *} \mathrm{p}<0.01$.

Table 1. The number of subjects assigned to each drug condition and their initial baseline context preference

\section{AMPH Effects on Locomotor Response,}

a Dose-Response Study

We examined whether animals showed a dose-dependent change in locomotor movement following acute administration of AMPH. A two-way ANOVA indicated that there were significant differences in the overall number of spontaneous forward movements initiated comparing baseline and test day locomotor responses. There was a main effect for time regardless of treatment $(\mathrm{F}(1$, $12)=14.63, p=0.0024$; fig. 4a). Frogs initiated fewer moves on day 2 compared to day 1 . However, there was no main effect for drug dose $(F(2,12)=1.22, p=0.33)$. In order to analyze the data independent of possible individual differences in behavior, we examined relative changes in number of movements (test minus baseline) across drug doses. One-way ANOVA indicated no significant differences in relative movement as a function of drug dose $(F(2,12)=2.45, p=0.12$; fig. $4 b)$. No other changes in motor patterns or stereotyped behaviors were observed.

\section{Discussion}

The results of this study are the first report of AMPH $\mathrm{CPP}$ in a non-mammalian vertebrate and are also the first report of the effects of AMPH on the motor responses of a vertebrate ectotherm. Our results indicate that the psychoactive drug AMPH can induce conditioned place

\begin{tabular}{lll}
\hline Drug condition & Baseline preference & Subjects, $\mathrm{n}$ \\
\hline \multirow{2}{*}{ AMPH } & black & 5 \\
& white & 3 \\
Ringer's & white & 4 \\
& black & 4 \\
\hline
\end{tabular}

preference in breeding-condition male Hyla cinerea, the green tree frog. We demonstrated that AMPH can reverse context preference in a CPP chamber following 14 days of conditioning. Preference was conditioned when AMPH (20 $\mathrm{mg} / \mathrm{kg}$ b.w.) was paired with a non-preferred context and vehicle was paired with the preferred context. In contrast, control animals that received vehicle injections in both contexts did not switch context preferences at the conclusion of the experiment, nor did these frogs show diminished strength of preference for the preferred context following 14 days of conditioning. Thus, the behavior of the animals receiving only vehicle injections indicate that although context preference is idiosyncratic, it is also stable over time. These results are consistent with AMPH's known effects on CPP in rodent models [Bardo and Bevins, 2000]. 


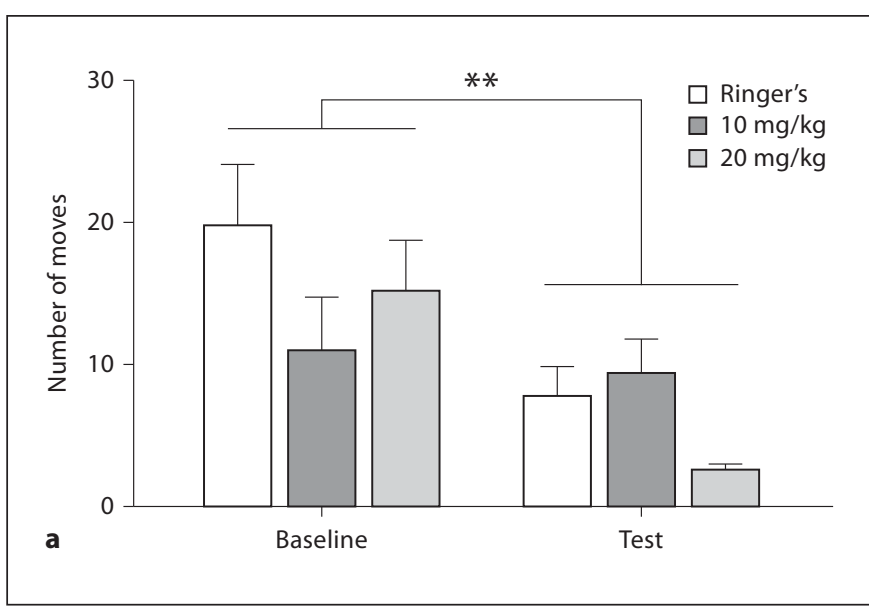

Fig. 4. a Number of movements made during the baseline and test conditions for vehicle- and AMPH- (10 and $20 \mathrm{mg} / \mathrm{kg}$ b.w.) treated animals. Animals moved less on test day regardless of drug treatment. ${ }^{* *} \mathrm{p}<0.01$. b Relative change in number of movements

Our results support the hypothesis that frogs possess a reward system that is pharmacologically similar to that of mammals and other vertebrates. Furthermore, our data are congruent with studies showing that cocaine, a related psychoactive drug, can cause CPP in non-mammalian vertebrates such as Japanese quail [Levens and Akins, 2001; Akins et al., 2004] and zebra fish [Darland and Dowling, 2001] and invertebrates such as crayfish [Panksepp and Huber, 2004].

The effective drug dose used in these experiments in frogs was greater than doses typically used in studies of mammals. Studies of non-mammalian vertebrates commonly demonstrate that effective drug doses differ among taxa. In particular, studies using amphibians often require a drug dose of one order of magnitude higher compared to equivalent studies in mammals. The drug doses used in this study are consistent with studies in other amphibians showing effective doses higher than those used in rodents models [Marler et al., 1995; Glagow and Ewert, 1999; Ten Eyck, 2008]. This increase in effective dose may account for physiological differences between amphibians and mammals, such as differences in metabolic rate (ectotherms vs. endotherms) or differences in receptor pharmacology [Chu et al., 2001]. Although a pharmacological characterization of AMPH has not been examined in amphibians, many mechanisms of dopamine pharmacology show a strong conservation of function. Such conservation of function include the neurotoxic effects of MPTP+ [Barbeau et al., 1985] and 6-hydroxydopamine

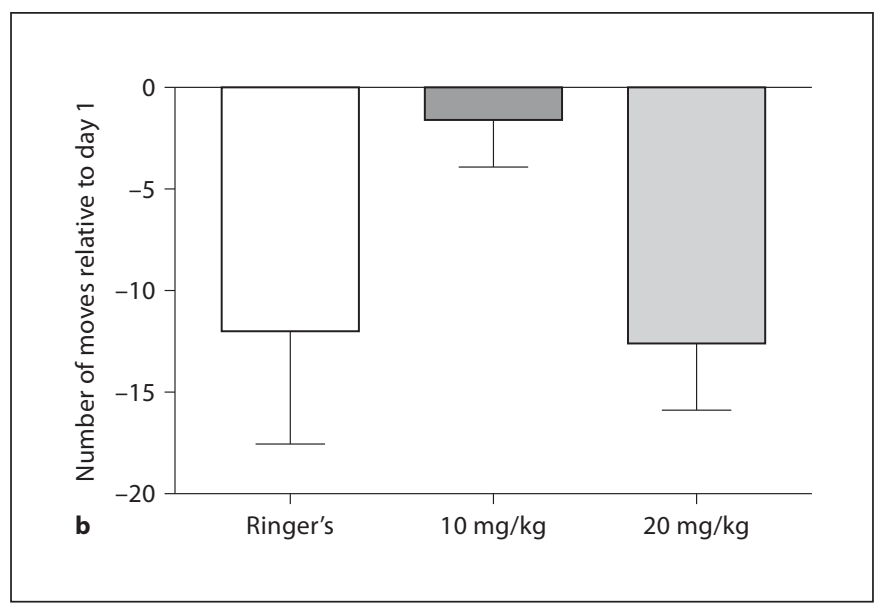

during the test condition relative to baseline. There were no significant differences in relative numbers of movements made across drug treatment.

[Endepols et al., 2004] on dopamine neurons in frog CNS, as well as behavioral effects of the mixed dopamine agonist apomorphine on motor behavior [Glagow and Ewert, 1999; Chu and Wilczynski, 2007; Chu and Rankine, 2008]. Dopamine D1- and D2-like receptors have been pharmacologically characterized in the brain of the northern leopard frog and have been shown to possess binding profiles for various dopaminergic ligands that are similar but not as potent as those of the rat striatum [Chu et al., 2001].

Unlike mammals that possess a strong preference for darker colored chambers [James et al., 2000], frogs possess strong idiosyncratic preferences. Half of the subjects had an initial preference for the white and smooth chamber side, the other half for black and rough. This lack of systemic bias was helpful in determining that changes in context preferences following conditioning were likely due to drug effects and not context bias.

AMPH is known for its classical effects of increasing motor responses and stereotypy in mammals [Segal and Kuczenski, 1994; Rebec, 1998]. Little is known of its motor effects in non-mammals. We examined the effects of $\mathrm{AMPH}$ on locomotor movements using the conditioning chamber as an open field arena. Pilot studies in our lab indicate that tree frogs exhibit a strong exploratory response to a novel environment. In this present motor study, we chose to test locomotor responses to $\mathrm{AMPH}$ administration following an initial pre-exposure to the conditioning chamber in order to reduce variation of 
behavior from a novelty effect. The number of forward movements initiated while in the chamber was assessed on the first day following a vehicle injection. The next day, animals were again placed in the chamber following an injection of 0,10 or $20 \mathrm{mg} / \mathrm{kg}$ b.w. AMPH. Animals moved significantly less on the second day relative to the first, presumably due to habituation to the chamber, but there was no effect of the drug either in the absolute number of movements made on the test day or in the number of movements initiated relative to baseline.

As number of movements initiated following AMPH was indistinguishable from controls, we do not believe that the drug doses used in our study impaired movement. High doses of AMPH in rodents are known to induce repetitive, stereotyped movement [Segal and Kuczenski, 1994; Rebec, 1998]. We quantified forward movement in our motor studies, as AMPH-treated frogs did not exhibit any other unusual behaviors that might constitute stereotypy. Although these results were unexpected, they do not support an alternative hypothesis that the effects of AMPH on conditioned place preference might be indirectly due to changes in exploratory behavior during conditioning.

The results of these studies indicate the first demonstration of a pharmacological mechanism underlying motivation and reward in an amphibian model. Reward systems of the brain are believed to have evolved to serve the occurrence of naturally motivated behavior such as feeding, water intake, sex behavior and social interactions in mammals, and not drug addiction [Berridge, 1996; Pfaus et al., 2001; Kelley and Berridge, 2002; Insel and Fernald, 2004]. It is not unreasonable to predict that such reward systems also exist to regulate motivated behaviors in non-mammals. Berridge has hypothesized that mesolimbic/mesocortical dopamine in particular mediates learned associations between conditioned stimuli and reward stimuli, thus increasing an animal's motivation to perform behaviors associated with reward [Berridge, 1996, 2007; Berridge and Robinson, 1998]. The results of our study, in combination with studies by others showing anatomical evidence for a mesolimbic dopamine system in frogs, suggest a homologous reward system functionally exists in amphibians.

Studies in mammals of neuroendocrine control of social motivation have posited that one function of the mesolimbic dopamine system is to facilitate socially appropriate behaviors by decreasing aversion towards conspecifics. Two such examples are the formation of monogamous pair bonds in voles and the displays of maternal behavior in rodents. Studies have shown that me- solimbic dopamine is integral in mediating pair bond formation in both male and female prairie voles [Liu and Wang, 2003; Wang and Aragona, 2004] and maternal response in rodents [Numan, 2007]. Social motivation in anurans can also be considered within a context of decreased aversion towards conspecifics. Metamorphosed frogs and toads are, in general, non-social and avoid conspecifics. In contrast, during the breeding periods many male frogs of species such as $H$. cinerea form dense breeding choruses near water sources and vocalize conspicuously in order to attract females to mate and to fend off competing males. Calling behavior is energetically demanding, and calling individuals are subject to increased predation and parasite load [McKeever and French, 2000; Wells, 2001]. While participating in a chorus, males will engage in calling behavior for several successive evenings to the exclusion of other activities, such as foraging. Reproductive success is directly related to calling effort in H. cinerea [Gerhardt et al., 1987]. When animals are not in breeding season, they do not aggregate nor do they vocalize. The results from this current study set a foundation to investigate whether a putative reward system in amphibians plays a role. It is our overall hypothesis that a reward system in these animals modulates socially motivated behaviors in amphibians as it does in mammals. These future studies can be applied to our understanding of the neurochemical control of social motivation in nonmammalian vertebrates and to extend our understanding of the dopamine system in general. The potential relationship between the dopamine system and socially motivated calling behavior is currently being investigated in ongoing experiments.

\section{Acknowledgments}

We would like to thank the two anonymous reviewers for their thorough comments on the original submission of the manuscript, Gertie for the illustration of the conditioning chamber, $\mathrm{Ni}$ cole Rankine for excellent technical support, and Brittany Johnson for her assistance on the behavioral experiments. This work was supported by HHMI Undergraduate Science Program Award No. 52005140 and NIH/NIGMS Research Initiative for Scientific Enhancement (RISE) at Spelman College, Atlanta, Ga., to G.M.P. Research support was provided by funding from the National Science Foundation, the NSF/STC - Center for Behavioral Neuroscience, IBN-9876754 and NIH/NCMHD RIMI, P20 MD000215, to J.C. 


\section{References}

Agmo A, Federman I, Navarro V, Padua M, Velazquez G (1993): Reward and reinforcement produced by drinking water: role of opioids and dopamine receptor subtypes. Pharmacol Biochem Behav 46:183-194.

-Akins CK, Levens N, Prather R, Cooper B, Fritz $T$ (2004): Dose-dependent cocaine place conditioning and d1 dopamine antagonist effects in male Japanese quail. Physiology Behav 82:309-315.

-Akins CK, Geary EH (2008): Cocaine-induced behavioral sensitization and conditioning in male Japanese quail. Pharmacol Biochem Behav 88:432-437.

Barbeau A, Dallaire L, Buu NT, Veilleux F, Boyer $\mathrm{H}$, de Lanney LE, Irwin I, Langston EB, Langston JW (1985): New amphibian models for the study of 1-methyl-4-phenyl-1,2,3,6tetrahydropyridine (MPTP). Life Sci 36: 1125-1134.

-Bardo M, Bevins R (2000): Conditioned place preference: what does it add to our preclinical understanding of drug reward. Psychopharm 153:31-43.

Berridge KC (1996): Food reward: brain substrates of wanting and liking. Neurosci Biobehav Rev 20:1-25.

Berridge KC, Robinson TE (1998): What is the role of dopamine in reward: hedonic impact, reward learning, or incentive salience? Brain Res Brain Res Rev 28:309-369.

Berridge KC (2007): The debate over dopamine's role in reward: the case for incentive salience. Psychopharmacology (Berl) 191:391-431.

Bilbo SD, Day LB, Wilczynski W (2000): Anticholinergic effects in frogs in a Morris water maze analog. Physiol Behav 69:351-357.

Brattstrom BH (1990): Maze learning in the firebellied toad, Bombina orientalis. J Herpetol 24:44-47.

Calcagnetti DJ, Schechter MD (1992): Place conditioning reveals the rewarding aspect of social interaction in juvenile rats. Physiol Behav 51:667-672.

Cheng HC, Bhatnagar RK, Long JP (1975): Dopaminergic nature of amphetamine-induced pecking in pigeons. Eur J Pharmacol 33:319324.

Chu J, Wilczynski W, Wilcox RE (2001): Pharmacological characterization of the $\mathrm{d} 1$ - and d2-like dopamine receptors from the brain of the leopard frog, Rana pipiens. Brain Behav Evol 57:328-342.

Chu J, Wilczynski W (2007): Apomorphine effects on frog locomotor behavior. Physiol Behav 91:71-76.

Chu J, Rankine N (2008): The effect of dopamine agonists on swimming and climbing behavior in the green tree frog, Hyla cinerea. Soc Neurosci Annul Meeting, Washington, DC.

Cohen JD, Blum KI (2002): Reward and decision. Neuron 36:193-198.

Cole SO (1967): Experimental effects of amphetamine: a review. Psychol Bull 68:81-90.
Darland T, Dowling JE (2001): Behavioral screening for cocaine sensitivity in mutagenized zebrafish. Proc Natl Acad Sci USA 98:11691-11696

Douglas LA, Varlinskaya EI, Spear LP (2004): Rewarding properties of social interactions in adolescent and adult male and female rats: impact of social versus isolate housing of subjects and partners. Dev Psychobiol 45: 153-162.

Endepols H, Schul J, Gerhardt HC, Walkowiak W (2004): 6-hydroxydopamine lesions in anuran amphibians: a new model system for Parkinson's disease? J Neurobiology 60:395410.

Gerhardt HC, Daniel RE, Perrill SA, Schramm S (1987): Mating behaviour and male mating success in the green tree frog. Anim Behav 35:1490-1503.

Glagow M, Ewert J (1999): Apomorphine alters prey-catching patterns in the common toad: behavioral experiments and (14)c-2-deoxyglucose brain mapping studies. Brain Behav Evol 54:223-242.

Gonzalez A, Tuinhof R, Smeets WJ (1993): Distribution of tyrosine hydroxylase and dopamine immunoreactivities in the brain of the south African clawed frog Xenopus laevis. Anat Embryol (Berl) 187:193-201.

Goodman IJ (1981): Amphetamine and apomorphine induced stereotyped behavior in adult pigeons. Pharmacol Biochem Behav 15:701704.

Grubb JC (1976): Maze orientation by Mexican toads, Bufo valliceps (Amphibia, anura, bufonidae), using olfactory and configurational cues. J Herpetol 10:97-104.

He X, Xiao L, Sui N (2009): Effects of sch23390 and spiperone administered into medial striatum and intermediate medial mesopallium on rewarding effects of morphine in day-old chicks. Eur J Pharmacol 2010;627:136-141.

Heatwole H, Sullivan B (eds) (1995): Amphibian Biology, vol 2: Social Behavior. Australia, Surrey Beatty \& Sons

Hinde RA (1982): Ethology: Its Nature and Relations with Other Sciences. New York, Oxford University Press.

Idemudia SO, McMillan DE (1984): Effects of damphetamine on spontaneous motor activity in pigeons. Psychopharmacology (Berl) 84:315-317.

Insel TR, Fernald RD (2004): How the brain processes social information: searching for the social brain. Annu Rev Neurosci 27:697-722.

James JR, Young R, Rosecrans JA (2000): Conditioned place preference: an approach to evaluating positive and negative drug-induced stimuli; in Buccafusco JJ (ed): Methods of Behavior Analysis in Neuroscience. Boca Raton, CRC Press, pp 81-90.
Jarosz PA, Kessler JT, Sekhon P, Coscina DV (2007): Conditioned place preferences (CPPS) to high-caloric 'snack foods' in rat strains genetically prone vs. resistant to dietinduced obesity: resistance to naltrexone blockade. Pharmacol Biochem Behav 86: 699-704.

Kelley AE, Berridge KC (2002): The neuroscience of natural rewards: relevance to addictive drugs. J Neurosci 22:3306-3311.

Lanuza E, Novejarque A, Martinez-Ricos J, Martinez-Hernandez J, Agustin-Pavon C, Martinez-Garcia F (2008): Sexual pheromones and the evolution of the reward system of the brain: the chemosensory function of the amygdala. Brain Res Bull 75:460-466.

Lett BT, Grant VL (1989): The hedonic effects of amphetamine and pentobarbital in goldfish. Pharmacol Biochem Behav 32:355-356.

Levens N, Akins CK (2001): Cocaine induces conditioned place preference and increases locomotor activity in male Japanese quail. Pharmacol Biochem Behav 68:71-80.

Levens N, Akins CK (2004): Chronic cocaine pretreatment facilitates Pavlovian sexual conditioning in male Japanese quail. Pharmacol Biochem Behav 79:451-457.

-Liu Y, Wang ZX (2003): Nucleus accumbens oxytocin and dopamine interact to regulate pair bond formation in female prairie voles. Neuroscience 121:537-544.

- Marin O, Gonzalez A, Smeets WJ (1995): Evidence for a mesolimbic pathway in anuran amphibians: a combined tract-tracing/immunohistochemical study. Neurosci Lett 190:183-186.

Marin O, Smeets WJ, Gonzalez A (1997): Basal ganglia organization in amphibians: catecholaminergic innervation of the striatum and the nucleus accumbens. J Comp Neurol 378:50-69.

-Marler CA, Chu J, Wilczynski W (1995): Arginine vasotocin injection increases probability of calling in cricket frogs, but causes call changes characteristic of less aggressive males. Horm Behav 29:554-570.

Martinez I, Paredes RG (2001): Only self-paced mating is rewarding in rats of both sexes. Horm Behav 40:510-517.

Martof BS (1962): Some observations on the role of olfaction among salientian amphibia. Physiol Zool 35:270-272.

McKeever S, French FE (2000): Corethrellidae (diptera), vectors of present and perhaps some of the earliest anuran trypanosomes. Third Ann Virtual Conf Vet Med: Diseases of Reptiles and Amphibians.

Meerts SH, Clark AS (2007): Female rats exhibit a conditioned place preference for nonpaced mating. Horm Behav 51:89-94.

Munro AD (1986): The effects of apomorphine, $\mathrm{d}$-amphetamine and chlorpromazine on the aggressiveness of isolated Aequidens pulcher (Teleostei, Cichlidae). Psychopharmacology (Berl) 88:124-128. 
Ninkovic J, Bally-Cuif L (2006): The zebrafish as a model system for assessing the reinforcing properties of drugs of abuse. Methods 39: 262-274.

Numan M (2007): Motivational systems and the neural circuitry of maternal behavior in the rat. Dev Psychobiol 49:12-21.

-Panksepp JB, Huber R (2004): Ethological analyses of crayfish behavior: a new invertebrate system for measuring the rewarding properties of psychostimulants. Behav Brain Res 153:171-180.

Panksepp JB, Lahvis GP (2006): Social reward among juvenile mice. Genes Brain Behav 6: 661-671.

-Pfaus JG, Kippin TE, Centeno S (2001): Conditioning and sexual behavior: a review. Horm Behav 40:291-321.

Rebec G (1998): Behavioral pharmacology of amphetamine; in Tarter R, Ott P, Ammerman R (eds): Handbook of Substance Abuse: Neurobehavioral Pharmacology. New York, Springer, pp 515-528.
-Sanchez-Camacho C, Lopez JM, Gonzalez A (2006): Basal forebrain cholinergic system of the anuran amphibian Rana Perez: evidence for a shared organization pattern with amniotes. J Comp Neurol 494:961-975.

Segal DS, Kuczenski R (1994): Behavioral pharmacology of amphetamine; in Cho AK, Segal DS (eds): Amphetamine and Its Analogs. Academic Press, pp 115-150.

Seiden LS, Sabol KE, Ricaurte GA (1993): Amphetamine: effects of catecholamine systems and behavior. Annu Rev Pharmacol Toxicol 32:629-677.

-Sherman JE, Roberts T, Roskam SE, Holman EW (1980): Temporal properties of the rewarding and aversive effects of amphetamine in rats. Pharmacol Biochem Behav 13:597-599.

Smeets WJ (1994): Phylogeny and Development of Catecholamine Systems in the CNS of Vertebrates. New York, University of Cambridge Press.
Smeets WJ, Gonzalez A (2000): Catecholamine systems in the brain of vertebrates: new perspectives through a comparative approach. Brain Res Brain Res Rev 33:308-379.

Ten Eyck GR (2008): Serotonin modulates vocalizations and territorial behavior in an amphibian. Behav Brain Res 193:144-147.

Tzschentke TM (2007): Measuring reward with the conditioned place preference (CPP) paradigm: update of the last decade. Addict Biol 12:227-462.

Wang Z, Aragona BJ (2004): Neurochemical regulation of pair bonding in male prairie voles. Physiol Behav 83:319-328.

Watson KK, Platt ML (2008): Neuroethology of reward and decision-making. Philos Trans $\mathrm{R}$ Soc Lond B Biol Sci 363:3825-3835.

Wells KB (2001): The energetics of calling in frogs; in Ryan MJ (ed): Anuran Communication. Washington, Smithsonian Institution Press, pp 45-60.

Zhao B, Debski EA (2005): Serotonergic reticular formation cells in Rana pipiens: categorization, development, and rectal projections. J Comp Neurol 487:441-456. 